\title{
Evaluation of Cerebrovascular Reserve in Patients Undergoing Carotid Artery Stenting and Its Usefulness in Predicting Significant Hemodynamic Changes During Temporary Carotid Occlusion
}

\author{
M. SPACEK ${ }^{1}$, C. STECHOVSKY ${ }^{1}$, M. HORVATH ${ }^{1}$, P. HAJEK ${ }^{1}$, P. ZIMOLOVA ${ }^{1}$, \\ J. VESELKA ${ }^{1}$ \\ ${ }^{1}$ Department of Cardiology, Motol University Hospital, Second Medical School, Charles \\ University, Prague, Czech Republic
}

Received May 22, 2015

Accepted September 18, 2015

On-line November 24, 2015

\section{Summary}

We investigated the usefulness of cerebrovascular reserve (CVR) testing to predict severe hemodynamic changes during proximally protected carotid artery stenting. Of 90 patients referred, 63 eligible underwent complete evaluation of the extent of carotid artery disease and transcranial Doppler ultrasound (TCD) assessment of CVR by means of a breath-holding test and ophthalmic artery flow pattern evaluation. Periprocedural TCD monitoring of the ipsilateral middle cerebral artery flow was performed in 24 patients undergoing proximally protected procedure (requiring induction of flow arrest within internal carotid artery). Abnormal CVR was significantly less common in patients with unilateral compared to bilateral carotid artery disease ( $26.3 \%$ vs. $76.9 \%, p=0.02)$, while ophthalmic artery flow reversal was rare in patients with unilateral carotid artery disease $(2.5 \%$ vs. $42.9 \%, \mathrm{p}<0.01)$. During the induction of carotid flow arrest, the average mean flow velocity drop following external carotid artery occlusion was low (3.5\%, p=0.67) compared to the induction of complete flow arrest $(32.8 \%$, $\mathrm{p}<0.01$ ). Six patients had a total mean flow velocity drop $>50 \%$, including 2 patients with normal pre-procedural CVR. Our results suggest that TCD evaluation of CVR is not a reliable predictor of hemodynamic changes induced during proximally protected carotid artery stenting in patients with unilateral carotid artery disease.

\section{Key words}

Cerebrovascular reserve - Carotid artery occlusion - Carotid artery stenting - Transcranial Doppler ultrasound - Cerebral collateral circulation

\section{Corresponding author}

M. Spacek, Department of Cardiology, Motol University Hospital, Second Medical School, Charles University, V Úvalu 84, 150 06, Prague 5, Czech Republic. Fax: +420224434920. E-mail: mildaspacek@gmail.com

\section{Introduction}

Carotid artery disease is an important risk factor for a stroke development and it has been estimated that stenosis of the internal carotid artery is responsible for up to $15-20 \%$ of the occurrence of all strokes or transient ischemic attacks (Sacco et al. 1995). The prevalence of carotid artery disease increases with age and its wide variability of clinical manifestation ranges from incidental asymptomatic findings to devastating or fatal stroke, with cerebral collateral circulation being considered one of the major modifying factors (Liebeskind 2003). In order to decrease the stroke burden, carotid endarterectomy has been used extensively to eliminate both hemodynamically significant stenosis as well as carotid artery plaques as a source of cerebral atheroemboli. Over time, carotid artery stenting has evolved into a reliable method so that it may now be offered as a first-line treatment to selected patients (Spacek and Veselka 2013). Nevertheless, because of the improvement in medical therapy, there is a concern regarding the indication for invasive treatment in asymptomatic patients with severe unilateral carotid stenosis. Therefore, the safety of the procedure is of 
a paramount importance in order to evaluate the true benefit. With an increasing use of proximal protection systems resembling a surgical clamp (inducing flow stagnation within internal carotid artery by sequential balloon occlusion of external and common carotid artery), it is necessary to understand collateral cerebral circulation in order to protect patients from periprocedural hypoperfusion, which has been proven to increase the risk of peri-procedural cerebral events (Ackerstaff et al. 2005, Caplan and Hennerici 1998).

Transcranial Doppler ultrasound (TCD) is a useful tool allowing testing of cerebrovascular reserve (CVR) and monitoring in real time of a patient's hemodynamic status during procedure (Spacek et al. 2015a). Its usefulness in predicting severe hemodynamic changes during the period of carotid flow arrest has, however, been poorly defined. In our study, we prospectively evaluated CVR in asymptomatic patients referred for carotid artery stenting and focused on the ability of a CVR examination to predict severe hemodynamic changes during proximally protected procedures in patients with unilateral carotid artery disease.

\section{Patients and Methods}

During the study period between October 2012 and December 2014, we evaluated 90 asymptomatic patients considered high-risk for carotid endarterectomy (either multiple comorbidities and/or "hostile neck" with difficult approach to bifurcation including restenosis after endarterectomy), who had been referred to our institution for endovascular treatment with a presumed internal carotid artery stenosis of $>70 \%$ based on an outpatient non-invasive examination. Prior to carotid angiography, the majority of patients underwent a complete ultrasound reevaluation of the cervical arteries, performed by an experienced sonographer, using color Doppler flow imaging and pulse-Doppler examination (Toshiba Nemio XG, Toshiba Corporation, Tokyo, Japan). Apart from that, the extent of carotid and vertebral artery disease was reassessed during conventional cerebral angiography with severe carotid artery disease defined as $>70 \%$ internal carotid artery stenosis according to the NASCET criteria (North American Symptomatic Carotid Endarterectomy Trial Collaborators 1991). Patients with significant external carotid artery disease ( $>70 \%$ stenosis) as well as with severe steno-occlusive disease of the vertebral arteries (abnormal flow pattern or retrograde flow) were excluded from the study (6 and 3 patients, respectively, predominantly with extensive carotid artery disease). Prior to TCD evaluation, all patients gave written informed consent for participation in the study, the study was performed in accordance with the Declaration of Helsinki of the World Medical Association, and the study protocol was approved by the local ethics committee.

Cerebrovascular reserve was assessed using Multi-Dop $\mathrm{T}$ digital transcranial Doppler ultrasound system (DWL Elektronische Systeme, Sipplingen, Germany) by means of a breath-holding test (Markus and Harrison 1992) with evaluation of the ophthalmic artery flow pattern by a sonographer unaware either of the target internal carotid artery stenosis severity, or the complexity of carotid artery disease. During breath-holding test, two 2.5-MHz transducers fitted on a headband and placed on the temporal bone windows, were used to obtain a continuous measurement of the mean flow velocities (MFV) in the middle cerebral arteries. The depth of insonation ranged $45-55 \mathrm{~mm}$. Patients with an insufficient insonation window ipsilateral to the target artery were excluded from the study (18 patients).

The breath-holding index (BHI) was calculated by dividing the percent increase of MFV occurring during breath holding by the time in seconds that subjects held their breath. A breath-holding period of at least $24 \mathrm{~s}$ (ranging 25-30 s) was considered sufficient based on previous reports (Alexandrov 2005) in association with careful attention to normal inspiration in order to avoid a Valsalva maneuver (Fig. 1). The study was performed after at least $5 \mathrm{~min}$ of initial rest period in a quiet room, with patients lying in a comfortable supine position without any visual or auditory stimulation. Maximal MFV was recorded $4 \mathrm{~s}$ after termination of the apnea interval. Patients were trained to perform the procedure correctly before proceeding to a definitive recording, which was performed 3 times with at least a 2-min interval between each test, to allow the cerebrovascular circulation to normalize. The average of the 3 measurements was calculated as the final value. Following breath-holding test, the direction of flow in both ophthalmic arteries at an insonation depth of $50 \pm 5 \mathrm{~mm}$ was obtained, with flow direction away from the probe (flow reversal) considered abnormal and suggestive of depleted CVR. With regard to the previously published values defining normal $\mathrm{BHI}$ range (Zavoreo and Demarin 2004, Jimenez-Caballero and Segura 2006, Bago-Rozankovic et al. 2009, Barret et al. 2001) and in accordance with our observation derived 
from the control group, we arbitrarily defined the cut-off values for impaired $\mathrm{BHI}$ as $<0.95$ and as completely depleted in the case of BHI $<0.69$ as reported by Vernieri et al. (1999).

Carotid artery stenting was performed according to standardized protocols by an experienced operator, who had performed more than 700 CAS procedures before the beginning of the study. The operator was unaware of the results of CVR testing and the choice of an optimal device was based on personal experience. Use of protection systems was mandatory in all patients, while filter protection systems were used in cases involving more difficult carotid artery access. In all study patients, continuous monitoring of the middle cerebral artery MFV ipsilateral to the target internal carotid artery was performed during procedure. For a proximally protected procedure, a MO.MA Cerebral Protection Device (Medtronic, Minneapolis, MN) was used. This system induces flow arrest within internal carotid artery by sequential balloon occlusion of the ipsilateral external and common carotid artery, thereby resembling a surgical (external) clamp. The completeness of flow arrest was confirmed by contrast agent stagnation within the internal carotid artery together with the absence of contrast agent induced high-intensity transient signals detected by TCD in the ipsilateral middle cerebral artery. As a cut-off for significant hypoperfusion during the period of flow arrest, we used a previously recommended $>50 \% \mathrm{MFV}$ drop from baseline values, a threshold considered to increase the risk of neurologic complications (Garami and Lumsden 2011). During sequential arterial occlusion, middle cerebral artery MFV readings were performed immediately after external carotid artery and at least $10-15 \mathrm{~s}$ after common carotid artery occlusion. This allowed measurement of the contribution of external carotid artery collateral flow and also provided sufficient time for collateral recruitment after complete flow arrest induction, as suggested by Hetzel et al. (2000).

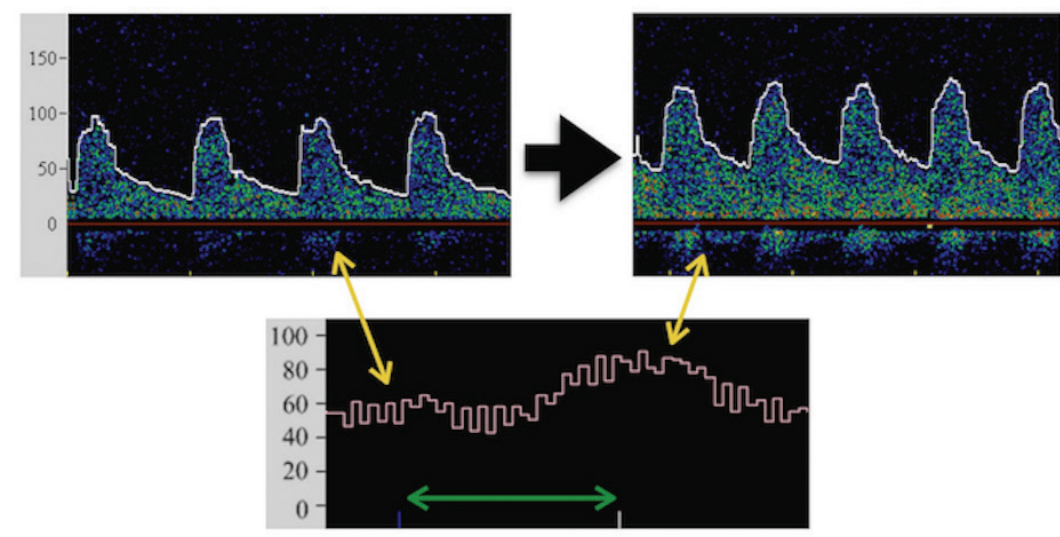

Fig. 1. Example of hemodynamic changes detected by TCD during a breath-holding test (patient from control group). Bottom: continuous middle cerebral artery MFV monitoring with breath-holding period marked by horizontal arrow. Top left: spectral Doppler trace obtained at baseline. Top right: spectral Doppler trace obtained $4 \mathrm{~s}$ after termination of apnea period. Both scales in $\mathrm{cm} / \mathrm{s}$.

Peri-procedural stroke was defined as a new neurological deficit that persisted for more than $24 \mathrm{~h}$; a minor stroke was defined as a new neurological deficit that resolved completely or returned to baseline within 30 days. Transient ischemic attack was defined as a new neurological deficit that persisted for less than $24 \mathrm{~h}$ and then completely resolved or returned to baseline. Balloon clamp intolerance was defined as a change in neurologic status with a direct relationship to the induction of flow arrest and subsequent resolution immediately after flow arrest termination. Asymptomatic patients were defined as those with no history of transient ischemic attack or minor stroke within 1 month or major stroke within 6 months prior to the procedure.

A GraphPad 6.05 statistical software (GraphPad Software, La Jolla, CA, USA) was used. Continuous variables were expressed as the mean $\pm \mathrm{SD}$ and categorical variables as counts and percentages. The Fisher's exact and Chi-square tests were used to compare categorical variables. The Mann-Whitney test was used to compare the medians of BHI values between study and control group and the medians of middle cerebral artery MFV changes during sequential balloon occlusions. The Kruskal-Wallis test with Dunn's multiple comparisons test was used to compare continuous variables in patients' baseline characteristics.

\section{Results}

Patients' baseline characteristics are summarized in Table 1. The study group consisted of 39 patients (67 77 years) with unilateral carotid stenosis of an average severity of $84 \pm 9 \%$. During carotid artery stenting, technical success was attained in all but 1 patient and this 
was because of severe vascular tortuosity. That patient subsequently opted for surgical treatment. Two minor strokes occurred: 1 patient developed a prolonged vagal reaction during postdilatation requiring repeated doses of atropine and high volumes of fluids, and the other patient problem occurred due to silent hypoperfusion during the period of flow arrest. In this patient, clinical intolerance developed during the final period of blood aspiration, requiring pre-term flow arrest termination, which was followed by several showers of microembolic signals that were detected by TCD. Both patients had near-complete neurological resolution by the time of hospital discharge and were symptom free at the 30-day follow-up visit.

Table 1. Comparison of the patients' baseline characteristics.

\begin{tabular}{|c|c|c|c|c|}
\hline & $\begin{array}{c}\text { Unilateral } \\
\text { Group } \\
\text { N=39 }\end{array}$ & $\begin{array}{c}\text { Bilateral } \\
\text { Group } \\
\mathrm{N}=14\end{array}$ & $\begin{array}{c}\text { Control } \\
\text { Group } \\
\mathbf{N}=\mathbf{1 0}\end{array}$ & p-value \\
\hline Sex (men) & $29(74 \%)$ & $11(79 \%)$ & $4(40 \%)$ & 0.08 \\
\hline Cholesterol (median; IQR) & $4.2(3.7-5.1)$ & $4(3.4-4.4)$ & $5.0(4.1-5.6)$ & 0.12 \\
\hline Triglycerides (median; IQR) & $1.5(1.2-2.3)$ & $1.7(1.3-2.0)$ & $1.3(0.9-2.6)$ & 0.76 \\
\hline Arterial hypertension & $38(97 \%)$ & $11(79 \%)$ & $9(90 \%)$ & 0.08 \\
\hline Diabetes mellitus & $12(31 \%)$ & $7(50 \%)$ & $6(60 \%)$ & 0.16 \\
\hline Peripheral arterial disease & $11(28 \%)$ & $6(43 \%)$ & $3(30 \%)$ & 0.60 \\
\hline Current smoking & $18(46 \%)$ & $6(43 \%)$ & $3(30 \%)$ & 0.65 \\
\hline Left ventricular ejection fraction $<40 \%$ & $3(8 \%)$ & $3(21 \%)$ & $0(0 \%)$ & 0.25 \\
\hline History of myocardial infarction & $14(36 \%)$ & $4(29 \%)$ & $3(30 \%)$ & 0.86 \\
\hline Severe renal insufficiency & $5(13 \%)$ & $5(36 \%)$ & $2(20 \%)$ & 0.17 \\
\hline Statin (pre-procedural use) & $30(77 \%)$ & $9(64 \%)$ & $6(60 \%)$ & 0.46 \\
\hline $\begin{array}{l}\text { ACE Inhibitor / Angiotensin receptor blocker } \\
\text { (pre-procedural use) }\end{array}$ & $31(79 \%)$ & $12(86 \%)$ & $7(70 \%)$ & 0.65 \\
\hline Betablocker (pre-procedural use) & $29(74 \%)$ & $8(57 \%)$ & $7(70 \%)$ & 0.48 \\
\hline Clopidogrel (pre-procedural use) & $18(46 \%)$ & $5(36 \%)$ & $2(20 \%)$ & 0.30 \\
\hline Acetylsalicylic acid (pre-procedural use) & $34(87 \%)$ & $13(93 \%)$ & $8(80 \%)$ & 0.65 \\
\hline
\end{tabular}

Ophthalmic artery flow reversal ipsilateral to target internal carotid artery stenosis was detected in only 1 patient and, as expected, was normal on the nonstenotic side in all patients. The average BHI values obtained ipsilateral and contralateral to the target internal carotid artery were $1.262 \pm 0.427$ and $1.432 \pm 0.397$ $(p=0.10)$, respectively. When compared to the subjects with excluded severe carotid artery disease $(72 \pm 4$ years, average BHI $1.608 \pm 0.308$, normal bilateral ophthalmic artery flow in all patients), the average BHI values were significantly lower ipsilateral to the target artery $(p<0.01)$. Figure 2 summarizes BHI values obtained from patients with unilateral and from subjects with excluded carotid artery disease.

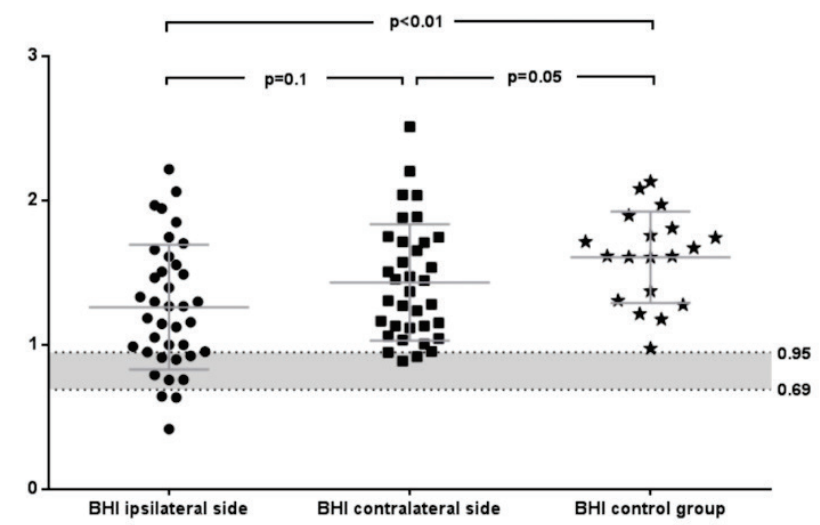

Fig. 2. Comparison of $\mathrm{BHI}$ values in patients with unilateral carotid artery disease (left and middle column) and in control group. Breath-holding test not completed in 1 patient unable to hold his breath for sufficient time period. BHI not available due to insufficient TCD window in 3 patients contralaterally to the target internal carotid artery and unilaterally in 1 control subject. 
Using the combined approach of abnormal BHI values and/or reversed ophthalmic artery flow, we were able to identify 10 patients $(26.3 \%)$ as having abnormal CVR, of which $6(15.8 \%)$ were categorized as having impaired and $4(10.5 \%)$ as having depleted CVR ( 3 based on BHI values and 1 with ophthalmic artery flow reversal). None of the patients with normal BHI values had impaired BHI on the non-stenotic side, while 2 of the patients with depleted CVR had impaired contralateral BHI values.

Fourteen patients $(68 \pm 5$ years $)$ had severe bilateral carotid artery disease. Tables 2 and 3 (patients with severe stenosis or occlusion contralateral to the target internal carotid artery, respectively) summarize their ophthalmic artery flow patterns and BHI values. Compared to the study group, ophthalmic artery flow reversal was identified in a significantly larger proportion of patients $(42.9 \%$ vs. $2.5 \%, \mathrm{p}<0.01)$. When combined with low BHI values, abnormal CVR in at least one territory was detected in a significantly larger percentage as well $(76.9 \%$ vs. $26.3 \%, \mathrm{p}=0.02)$.

Table 2. BHI values and ophthalmic artery flow patterns in patients with bilateral carotid artery disease without carotid artery occlusion.

\begin{tabular}{lcccccc}
\hline Patient & $\begin{array}{c}\text { Left internal } \\
\text { carotid artery } \\
\text { stenosis (\%) }\end{array}$ & BHI left & $\begin{array}{c}\text { Ophthalmic } \\
\text { artery flow } \\
\text { reversal }\end{array}$ & $\begin{array}{c}\text { Right internal } \\
\text { carotid artery } \\
\text { stenosis (\%) }\end{array}$ & BHI right & $\begin{array}{c}\text { Ophthalmic } \\
\text { artery flow } \\
\text { reversal }\end{array}$ \\
\hline 1 & 80 & $\mathbf{0 . 4 9 5}$ & - & 80 & $\mathbf{0 . 7 8 9}$ & - \\
2 & 70 & 1.576 & - & 80 & 1.968 & - \\
3 & 99 & $\mathbf{0 . 5 4 5}$ & - & 80 & 1.375 & - \\
4 & 70 & 2.008 & - & 95 & 1.624 & - \\
5 & 75 & $\mathbf{0 . 1 7 6}$ & - & 95 & $\mathbf{0 . 4 3 1}$ & + \\
6 & 70 & NA & - & 85 & 1.333 & - \\
7 & 70 & 1.061 & - & 75 & 1.010 & - \\
\hline
\end{tabular}

Table 3. BHI values and ophthalmic artery flow patterns in patients with bilateral carotid artery disease including carotid artery occlusion contralateral to target internal carotid artery.

\begin{tabular}{lccccc}
\hline Patient & $\begin{array}{c}\text { BHI } \\
\text { occluded side }\end{array}$ & $\begin{array}{c}\text { Ophthalmic } \\
\text { artery flow } \\
\text { reversal }\end{array}$ & $\begin{array}{c}\text { Internal carotid } \\
\text { artery stenosis } \\
\text { severity (\%) }\end{array}$ & $\begin{array}{c}\text { BHI } \\
\text { stenotic side }\end{array}$ & $\begin{array}{c}\text { Ophthalmic } \\
\text { artery flow } \\
\text { reversal }\end{array}$ \\
\hline 1 & $\mathbf{0 . 1 7 8}$ & - & 95 & $\mathbf{0 . 1 2 1}$ & - \\
2 & NA & + & 70 & 1.199 & - \\
3 & 1.040 & + & 75 & 1.062 & - \\
4 & $\mathbf{0 . 8 8 0}$ & + & 90 & 1.511 & - \\
5 & $\mathbf{0 . 2 5 0}$ & + & 90 & 1.263 & - \\
6 & $\mathbf{0 . 6 0 0}$ & + & 90 & $\mathbf{0 . 7 0 5}$ & - \\
7 & $\mathbf{0 . 5 8 8}$ & - & 70 & $\mathbf{0 . 7 6 9}$ & - \\
\hline
\end{tabular}

In all 24 patients with unilateral carotid artery disease treated with proximally protected carotid stenting, procedural monitoring of ipsilateral middle cerebral artery MFV was successfully completed. The average baseline MFV was $48.9 \mathrm{~cm} / \mathrm{s}$ and the velocity drop following external carotid artery balloon occlusion was low $(3.5 \%, \mathrm{p}=0.67)$, compared to the induction of total flow arrest $(32.8 \%, \mathrm{p}<0.01)$ (Fig. 3). In the only patient with reversed ophthalmic artery flow (and $95 \%$ target internal carotid artery stenosis), the velocity drop was more prominent with external carotid artery occlusion and followed by only a slight flow decrease after total 
flow arrest induction (baseline $35 \mathrm{~cm} / \mathrm{s}$, post-ECA occlusion $19 \mathrm{~cm} / \mathrm{s}$ and post-CCA occlusion $16 \mathrm{~cm} / \mathrm{s}$ ). Six patients developed significant middle cerebral artery MFV drop of $>50 \%$ from baseline values. However, pre-procedural CVR evaluation identified only 4 of these patients to have abnormal CVR, while 2 patients had normal ophthalmic artery flow patterns as well as BHI values (BHI ipsilateral to target internal carotid artery: 2.062 and 1.489 , internal carotid artery stenosis $80 \%$ and $70 \%$, respectively). In the patient with a pre-procedural BHI value of 1.489 , clinical intolerance developed immediately after sequential balloon occlusion with nearcomplete MCA flow arrest (Fig. 4), suggesting insufficient collateral support. Immediate flow arrest termination led to a prompt and complete resolution of neurological symptoms and the procedure was successfully completed using filter-type protection.

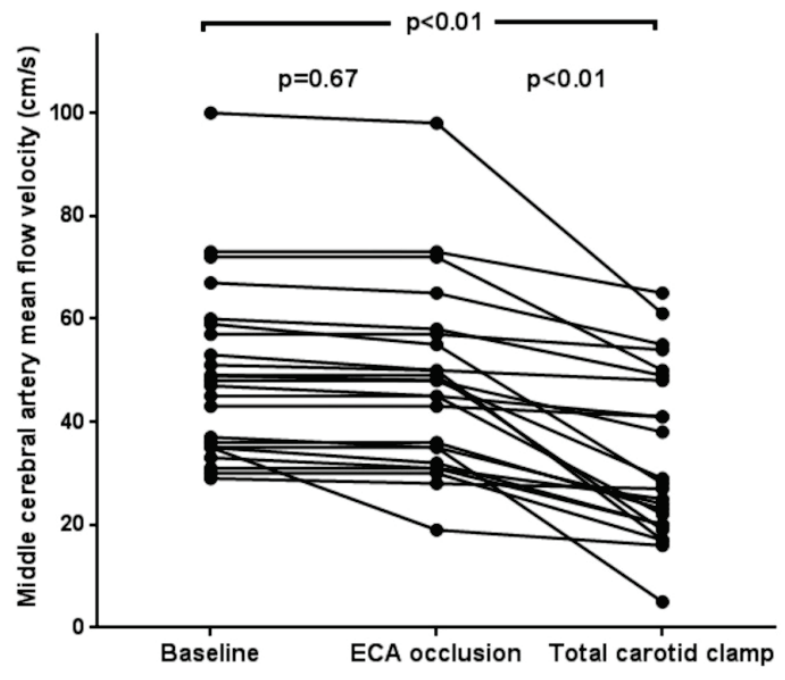

Fig. 3. Middle cerebral artery MFV changes during flow arrest. ECA - external carotid artery.

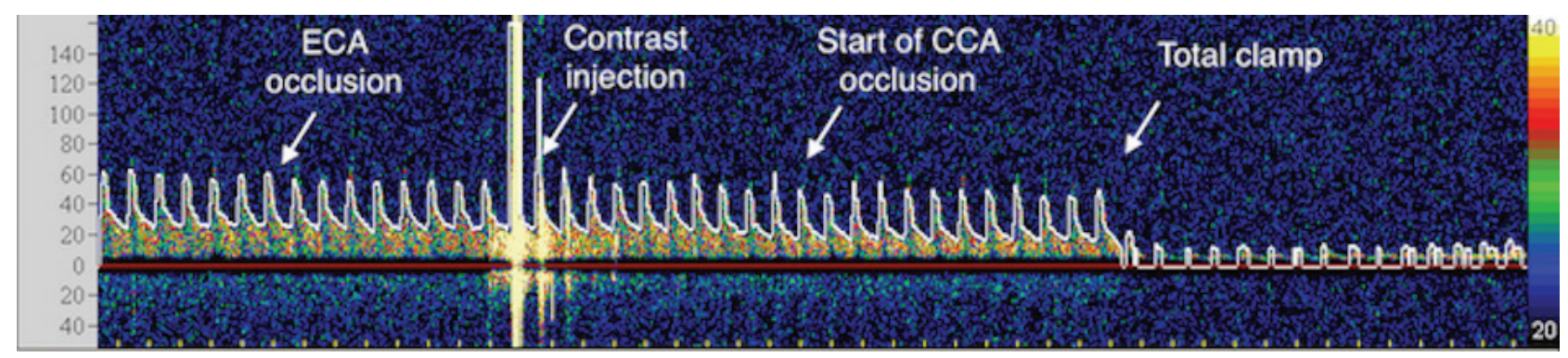

Fig. 4. Spectral Doppler trace of middle cerebral artery flow ipsilateral to target artery during the period of flow arrest induction in the patient with clinical balloon clamp intolerance. ECA - external carotid artery, CCA - common carotid artery. Scale in cm/s.

\section{Discussion}

In our study, we present our single-center experience with consecutive patients referred for carotid artery stenting in whom CVR was prospectively evaluated by means of TCD. Moreover, we used the induction of flow arrest within internal carotid artery during proximally protected procedures as a test to assess the ability of CVR to predict severe hemodynamic changes during total carotid artery occlusion. Based on our results, we suggest that pre-procedural TCD testing is not a reliable predictor of severe hemodynamic changes in unselected patients with unilateral carotid stenosis undergoing proximally protected carotid artery stenting.

Proximal protection systems currently represent one of the most promising improvements of the carotid stenting procedure. These systems essentially reproduce the hemodynamic condition brought about by surgical (external) clamping, but do not have the ability to shunt the lesion. Despite being effective in reducing the amount of emboli particles released during the period of flow arrest (Montorsi et al. 2011), the trade-off is that the ipsilateral hemisphere is totally dependent on the collateral cerebral circulation and may suffer from "silent hypoperfusion" as well as may be more susceptible to residual embolic load commonly observed during balloon deflations (Spacek and Veselka 2014). This may partly explain why inconsistent results have been reported regarding the superior safety of these systems (Bijuklic et al. 2012, de Castro-Afonso et al. 2013). The ability to assess in advance the risk of hypoperfusion induced during the period of flow arrest might help in identifying those for whom such an approach would be inappropriate, thereby potentially increasing the safety of the procedure.

Cerebral collateral circulation plays an important role in stroke development and is responsible for hemodynamic compensation in patients undergoing temporary carotid occlusion. While the circle of Willis (particularly the anterior communicating artery) is considered the most important (primary) collateral source 
immediately able to support/restore middle cerebral artery flow, the ophthalmic artery is considered to be a secondary collateral pathway requiring time to come into play (Spacek et al. 2015b, Hofmeijer et al. 2002). It has been reported that large inter-individual variability can be found regarding the completeness of the circle of Willis with up to $10 \%$ of individuals having a hypoplastic anterior communicating artery and with almost every fourth person having hypoplasty of the posterior collateral circulation (Iqbal 2013).

Several authors have tried to estimate the role of pre-procedural TCD to detect severe hemodynamic changes during temporary carotid occlusion. Interestingly, it has been suggested that a pre-procedural carotid compression test might be useful in determining the patients who would tolerate carotid occlusion well (Anzola et al. 2008). This test, however, carries a risk of stroke due to mobilization of plaque content. Conversely, little is known about the use of pre-procedural CVR evaluation and most of the data come from studies with patients undergoing surgical carotid endarterectomy, resulting in ambiguous conclusions (Telman et al. 2007, Visser et al. 2000). The drawback of these studies were unselected inclusion of patients with both unilateral and bilateral carotid artery disease, lack of evaluation of ophthalmic artery flow, and the use of a shunt requirement as an endpoint, all of which make interpretation difficult and the results not generalizable to patients undergoing a proximally protected carotid artery stenting.

In our study, we first defined the CVR patterns in unselected consecutive patients referred for carotid artery stenting with emphasis on ophthalmic artery flow assessment. Interestingly, Fearn et al. (2000) evaluated the contribution of external carotid artery flow to the cerebral circulation in unselected patients (including both those with unilateral and bilateral carotid artery disease) undergoing surgical carotid endarterectomy and concluded that external carotid artery may significantly contribute to the ipsilateral middle cerebral artery flow. However, Rutgers et al. (2000) observed in their large series that ophthalmic artery flow reversal was never present in patients with internal carotid artery stenosis of $80 \%$ or less. We observed that ophthalmic artery flow reversal was dependent on the severity of carotid artery disease and prevailed in the group of patients with the most extensive bilateral disease, but was rare in patients with unilateral stenosis. Therefore, the finding of abnormal CVR in the study group more commonly represented by impaired $\mathrm{BHI}$ values underscores the importance of the ophthalmic artery as the last-option collateral that becomes activated when primary collaterals fail. In accordance with this finding, a relatively minor contribution of external carotid artery to middle cerebral artery flow was observed during selective external carotid artery occlusion as compared to total flow arrest.

It is well known that carotid artery stenting produces larger amounts of cerebral embolism compared to carotid endarterectomy, in which a hemodynamic stroke may contribute to the risk of a peri-procedural neurologic complication (Jordan et al. 1999). While shunt insertion may improve the hemodynamic situation in patients undergoing surgical procedure, no such intervention is possible during proximally protected carotid artery stenting. Interestingly, Stabile et al. (2010) in their large experience with 1300 patients (87.5\% with unilateral carotid artery disease) who were managed with a proximally protected procedure, reported that, despite clinical tolerance by most of the patients of the flow arrest, up to every fifth patient developed signs of clinical intolerance during the period of active blood aspiration, suggesting that a large proportion of patients had borderline or compromised cerebral blood flow during the period of flow arrest. Indeed, we observed in our study that 6 of the 24 patients treated with a proximally protected procedure had a middle cerebral artery MFV drop of more than $50 \%$ form baseline values, a cut-off considered to increase the risk of procedural complications. In that case, we apply a slow TCD-guided blood aspiration technique to prevent the development of clinical intolerance requiring pre-term balloon deflations. However, we observed that such a situation might develop despite normal pre-procedural CVR values, suggesting that residual flow through the target internal carotid artery may be sufficient to mask compromised cerebral collateralization, thereby making pre-procedural CVR evaluation unreliable in the prediction of hemodynamic changes during balloon clamping.

\section{Limitations of the study}

The limitation of our study is a relatively low patient population. A significantly larger number of patients will be needed to confirm whether the results are generalizable to patients with both high-grade (90-99\%) and low-grade (70-89\%) internal carotid artery stenosis. However, with the decreasing numbers of asymptomatic 
patients referred for invasive treatment, it is currently unlikely that such a study will be performed without a multi-center design.

\section{Conclusion}

The majority of asymptomatic patients with severe unilateral carotid artery stenosis show good tolerance of proximally protected carotid artery stenting with temporary carotid occlusion. Despite that, cerebral blood flow is significantly decreased in a subgroup of patients, exposing them to the potential risk of silent hypoperfusion, with a resultant increase in susceptibility to neurologic complications. Transcranial Doppler ultrasound, despite its usefulness in procedural monitoring, is not a reliable tool for prediction of severe hemodynamic changes in patients with unilateral carotid stenosis who are undergoing proximally protected carotid artery stenting.

\section{Conflict of Interest}

There is no conflict of interest.

\section{Acknowledgements}

The research was supported by projects of the Ministry of Health of the Czech Republic: Conceptual Development of Research Organization 00064203 and AZV 15-34904A.

\section{References}

ACKERSTAFF RG, SUTTORP MJ, VAN DEN BERG JC, OVERTOOM TT, VOS JA, BAL ET, ZANEN P: Prediction of early cerebral outcome by transcranial Doppler monitoring in carotid bifurcation angioplasty and stenting. J Vasc Surg 41: 618-624, 2005.

ALEXANDROV AV: The role of ultrasound in the management of cerebrovascular disease. In: Introduction to Vascular Ultrasonography. Fifth edition. WJ ZWIEBEL, JS PELLERITO (eds), Elsevier Sounders, Philadelphia, 2005, pp 107-132.

ANZOLA GP, LIMONI P, CAVRINI G: Predictors of carotid clamping intolerance during endarterectomy that would be wise to apply to stenting procedures. Cerebrovasc Dis 26: 494-501, 2008.

BAGO-ROZANKOVIC P, LOVRENCIC-HUZJAN A, STRINEKA M, BASIC S, DEMARIN V: Assessment of breath holding index during orthostasis. Acta Clin Croat 48: 299-304, 2009.

BARRET KM, ACKERMAN RH, GAHN G, ROMERO JM, CANDIA M: Basilar and middle cerebral artery reserve: a comparative study using transcranial Doppler and breath-holding techniques. Stroke 32: 2793-2796, 2001.

BIJUKLIC K, WANDLER A, HAZIZI F, SCHOFER J: The PROFI Study (Prevention of Cerebral Embolization by Proximal Balloon Occlusion Compared to Filter Protection During Carotid Arty Stenting): a prospective randomized trial. J Am Coll Cardiol 59: 1383-1389, 2012.

CAPLAN LR, HENNERICI M: Impaired clearance of emboli (washout) is an important link between hypoperfusion, embolism, and ischemic stroke. Arch Neurol 55: 1475-1482, 1998.

De CASTRO-AFONSO LH, ABUD LG, ROLO JG, DOS SANTOS AC, DE OLIVEIRA L, BARRIERA CM, VELASCO TR, PONTES-NETO OM, ABUD DG: Flow reversal versus filter protection: a pilot carotid artery stenting randomized trial. Circ Cardiovasc Interv 6: 552-559, 2013.

FEARN SJ, PICTON AJ, MORTIMER AJ, PARRY AD, MCCOLLUMN CN: The contribution of the external carotid artery to cerebral perfusion in carotid disease. J Vasc Surg 31: 989-993, 2000.

GARAMI Z, LUMSDEN AB: Intra-operative TCD Monitoring. In: Cerebrovascular Ultrasound in Stroke Prevention and Treatment. Second Edition. AV ALEXANDROV (ed.), Wiley-Blackwell Publishing, Oxford, UK, 2011, pp 214-227.

HETZEL A, VON REUTERN G, WERNZ MG, DROSTE DW, SCHUMACHER M: The carotid compression test for therapeutic occlusion of the internal carotid artery. Comparison of angiography with transcranial Doppler sonography. Cerebrovasc Dis 10: 194-199, 2000.

HOFMEIJER J, KLIJN CJ, KAPPELLE LJ, VAN HUFFELEN AC, VAN GIJN J: Collateral circulation via the opthalmic artery or leptomeningeal vessels is associated with impaired cerebral vasoreactivity in patients with symptomatic carotid artery occlusion. Cerebrovasc Dis 14: 22-26, 2002. 
IQBAL S: A comprehensive study of the anatomical variations of the circle of Willis in adult brains. J Clin Diagn Res 7: 2423-2427, 2013.

JIMENEZ-CABALLERO PE, SEGURA T: Normal values of cerebral vasomotor reactivity using the breath-holding test. Rev Neurol 43: 598-602, 2006.

JORDAN WD JR, VOELLINGER DC, DOBBLAR DD, PLYUSHCHEVA NP, FISHER WS, MCDOWELL HA: Microemboli detected by transcranial Doppler monitoring in patients during carotid angioplasty versus carotid endarterectomy. Cardiovasc Surg 7: 33-38, 1999.

LIEBESKIND DS: Collateral circulation. Stroke 34: 2279-2284, 2003.

MARKUS HS, HARRISON MJ: Estimation of cerebrovascular reactivity using transcranial Doppler, including the use of breath-holding as the vasodilatory stimulus. Stroke 23: 668-673, 1992.

MONTORSI P, CAPUTI L, GALLI S, CICERI E, BALLERINI G, AGRIFOGLIO M, RAVAGNANI P, TRABATTONI D, PONTONE G, FABBIOCCHI F, LOALDI A, PARATI E, ANDREINI D, VEGLIA F, BAARTORELLI AL: Microembolization during carotid artery stenting in patients with high-risk, lipid-rich plaque. A randomized trial of proximal versus distal cerebral protection. J Am Coll Cardiol 58: 1656-1663, 2011.

NORTH AMERICAN SYMPTOMATIC CAROTID ENDARTERECTOMY TRIAL COLLABORATORS: Beneficial effect of carotid endarterectomy in symptomatic patients with high-grade carotid stenosis. $N$ Engl J Med $\mathbf{3 2 5}$ : 445-453, 1991.

RUTGERS DR, KLIJN CJ, KAPELLE LJ, VAN HUFFELEN AC, VAN DER GROND J: A longitudinal study of collateral flow patterns in the circle of Willis and the ophthalmic artery in patients with a symptomatic internal carotid artery occlusion. Stroke 31: 1913-1920, 2000.

SACCO RL, KARGMAN DE, GU Q, ZAMANILLO MC: Race-ethnicity and determinants of intracranial atherosclerotic cerebral infarction. The Northern Manhattan Stroke Study. Stroke 226: 14-20, 1995.

SPACEK M, VESELKA J: Carotid artery stenting - current status of the procedure. Arch Med Sci 9: 1028-1034, 2013.

SPACEK M, VESELKA J: Microembolization following balloon deflation during proximally protected carotid artery stenting - a potential focus of procedure improvement? Catheter Cardiovasc Interv 83: 1185-1186, 2014.

SPACEK M, SORRELL VL, VESELKA J: Transcranial Doppler ultrasound in the current era of carotid artery stenting. Ultraschall Med 36: 337-341, $2015 \mathrm{a}$.

SPACEK M, TESAR D, VESELKA J: The paramount role of the anterior communicating artery in the collateral cerebral circulation. Int J Angiol 24: 236-240, $2015 \mathrm{~b}$.

STABILE E, SALEMME L, SORROPAGO G, TESORIO T, NAMMAS W, MIRANDA M, POPUSOI G, CIOPPA A, AMBROSINI V, COTA L, PETRONI G, DElla PIETRA G, AUSANIA A, FONTANELli A, BIAMINO G, RUBINO P: Proximal endovascular occlusion for carotid artery stenting: results from a prospective registry of 1,300 patients. J Am Coll Cardiol 55: 1661-1667, 2010.

TELMAN G, KOUPERBERG E, NITECKI S, KARRAM T, SCHWARZ HA, SPRECHER E, HOFFMAN A, YARNITSKY D: Preoperative cerebral hemodynamics and shunting during carotid endarterectomy in patients with severe unilateral carotid stenosis. J Clin Ultrasound 35: 498-503, 2007.

VERNIERI F, PASQUALETTI P, PASSARELLI F, ROSSINI PM, SILVESTRINI M: Outcome of carotid artery occlusion is predicted by cerebrovascular reactivity. Stroke 30: 593-598, 1999.

VISSER GH, WIENEKE GH, VAN HUFFELEN AC, EIKELBOOM BC: The use of preoperative transcranial Doppler variables to predict which patients do not need a shunt during carotid endarterectomy. Eur J Vasc Endovasc Surg 19: 226-232, 2000.

ZAVOREO I, DEMARIN V: Breath holding index in the evaluation of cerebral vasoreactivity. Acta Clin Croat 43: $15-19,2004$. 